\title{
Viabilidade técnica, socioeconômica e ambiental de sistema fotovoltaico em posto de combustível no município de Vinhedo, Brasil
}

\author{
Submetido-11 dez. 2020 Aprovado-01 maio 2021 Publicado-17 maio 2021
}

http://dx.doi.org/10.52755/sas.v2i1.104

\begin{abstract}
Graduado em Engenharia Ambiental e Sanitária, Centro Universitário Padre Anchieta (UniAnchieta) Jundiaí, SP, Brasil. E-mail: luis.galdino.oliveira@outlook.com.
\end{abstract}

Luís Carlos Galdino de Oliveira

Elidiane Aparecida de Oliveira Graduada em Engenharia Ambiental e Sanitária, Centro Universitário Padre Anchieta (UniAnchieta) Jundiaí, SP, Brasil. E-mail: elidiane_2803@hotmail.com.

Raquel Carnivalle Silva Melillo

Doutora em Ambiente e Sociedade pela Universidade Estadual de Campinas. Professora do Centro Universitário Padre Anchieta (UniAnchieta) - Jundiaí, SP, Brasil. E-mail: raquel.melillo@anchieta.br.

Cristiane Ronchi de Oliveira

Doutora em Ciências Ambientais pela Universidade Estadual "Júlio de Mesquita Filho", Professora do Centro Universitário Padre Anchieta (UniAnchieta) - Jundiaí, SP, Brasil. E-mail: cristiane.oliveira@anchieta.br.

\section{Felipe Rosafa Gavioli}

Mestre em Agroecologia e Desenvolvimento Rural pela Universidade Federal de São Carlos, Professor do Centro Universitário Padre Anchieta (UniAnchieta) - Jundiaí, SP, Brasil. E-mail: felipe.gavioli@anchieta.br.

\section{RESUMO}

0 uso de energia elétrica tem se tornado primordial para as atividades atuais, uma vez que 0 crescimento populacional, industrial e tecnológico, contribui cada vez mais para o aumento da demanda energética. Porém, o atual cenário relacionado à escassez e o potencial de poluição dos combustíveis fósseis têm gerado grandes discussões em âmbito mundial. Desta forma, a busca por fontes renováveis se torna mais recorrente, uma das alternativas que empregada é a energia solar, pois se trata de uma fonte de energia sustentável cada vez mais acessível. 0 presente estudo teve como objetivo analisar um sistema de energia solar fotovoltaico já inserido em um posto de combustível no município de Vinhedo no Estado de São Paulo, com intuito de evidenciar as questões técnicas, econômicas e socioambientais. Para isso, realizouse um estudo bibliográfico, com fontes de pesquisas primárias e secundárias, o qual se complementou pelo estudo de caso descritivo, com caráter qualitativo. Os resultados obtidos confirmaram a viabilidade do sistema em questão, em todos os aspectos com inúmeros benefícios. Entretanto, a falta de conhecimento na sociedade relativa a tecnologias limpas é uma preocupação crescente.

Palavras-chave: Demanda energética; fontes renováveis; tecnologias limpas.

Este é um trabalho de acesso aberto e distribuído sob os Termos da Creative Commons Attribution Attribution-NonCommercial-ShareAlike 4.0 International.

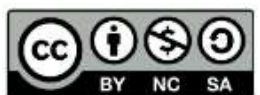




\title{
Technical, socioeconomic and environmental feasibility of a photovoltaic system at a gas station in the municipality of Vinhedo, Brazil
}

\begin{abstract}
Electrical energy is essential for human activities. Demographic growth, industrial and technological development increasingly contributes to energy demand increase. However, our current scenario related to scarcity and pollution potential of fossil fuels is generating great discussions worldwide. Therefore, the search for renewable energy sources is becoming more frequent. One of the many options that has being used is solar energy, since it is a source of sustainable energy becoming more affordable. This study sets out to analyze a photovoltaic energy system already inserted in a fuel center located in Vinhedo city, state of São Paulo. The intention is pointing out technical, economics and socioenvironmental viability. A qualitative and bibliographic study was conducted with primary and secondary sources, complemented by a case study. Results achieved validated the system on all observed elements with multiple benefits identified. However, the lack of knowledge of society related to clean technologies is a growing concern.
\end{abstract}

Keywords: Energy demand; renewable sources; clean technologies.

\section{Viabilidad técnica, socioeconómica y ambiental de un sistema fotovoltaico en una gasolinera del municipio de Vinhedo, Brasill}

\begin{abstract}
RESUMEN
El uso de la energía eléctrica es fundamental para las actividades humanas, ya que el crecimiento de la población y el desarrollo industrial y tecnológico han contribuido cada vez más al aumento de la demanda energética. Sin embargo, la escassez actual y el potencial de contaminación de los combustibles fósiles han generado importantes debates en todo el mundo. La búsqueda de fuentes renovables es cada vez más recurrente, y una de las alternativas que se estan utilizando es la energía solar, porque es una fuente de energía sostenible cada vez más accesible. El presente estudio tuvo como objetivo evaluar un sistema de energía solar fotovoltaica ya insertado en una gasolinera en el municipio de Vinhedo en el estado de São Paulo, con el fin de analizar los problemas técnicos, económicos y socioambientales. Para eso, se realizó uma encuesta bibliográfica, con fuentes de información primaria y secundaria, que se complementó con el estudio de caso descriptivo, con carácter cualitativo. Los resultados obtenidos confirmaron la viabilidad del sistema en cuestión en todos los aspectos con numerosos beneficios, sin embargo, la falta de conocimiento en la sociedade acerca de tecnologías limpias es una preocupación creciente.
\end{abstract}

Palabras clave: Demanda energética; fuentes renovables; tecnologías limpias.

\section{Introdução}

A utilização da energia elétrica é indispensável para o desenvolvimento tecnológico e socioeconômico. Neste sentido, a demanda por eletricidade está sempre em crescimento, assim como a população, dependente de recursos não-renováveis (SCARLATO; PONTIM, 2001). Os combustíveis fósseis foram e ainda são um dos grandes pilares que movimentam a industrialização. Entretanto, foram utilizados por muito tempo 
como se fossem infinitos. Nos últimos anos, o risco da escassez e os impactos ao meio ambiente tornaram a preocupação uma questão política e econômica, merecedora de investimentos para pesquisas e programas de incentivos que buscam alternativas sustentáveis para as gerações presentes e futuras (WALISIEWICZ, 2008).

Os combustíveis fósseis são responsáveis pela liberação dos Gases de Efeito Estufa (GEE) e, consequentemente, levam ao aquecimento global. Dessa forma, os desafios ambientais para substituí-los por alternativas mais limpas são prioritários. Trata-se de uma transição de paradigmas que precisa ser implementada com mais veemência no Brasil, pois as energias renováveis diversificam a matriz energética e, em sua maioria, beneficiam a sociedade e a biodiversidade (JARDIM, 2007).

As energias renováveis são aquelas cujas fontes não se esgotam, são mantidas e regeneradas pelos processos naturais, o que garante estabilidade e benefícios para toda a população. Dentre as energias renováveis, pode-se evidenciar a energia solar, eólica, das águas e biomassa (GOLDEMBERG; LUCON, 2007). Entretanto, há possibilidade de impactos locais como no caso da energia proveniente de hidrelétricas que é a principal fonte energética da matriz brasileira. A instalação das hidrelétricas inunda áreas extensas, desencadeando impactos para fauna, destruição da vegetação natural, deslocamento de populações ribeirinhas e indígenas, bem como da biodiversidade, além do assoreamento dos rios e mudanças dos ecossistemas da região (JARDIM et al., 2004).

As energias renováveis que passam a ser mais utilizadas e discutidas são a biomassa, a eólica e a solar. A energia advinda da biomassa emprega os derivados de organismos vivos, que seriam designados como resíduos, na produção de energia, minimizando o impacto de seu descarte e aproveitando seu potencial (GOLDEMBERG; LUCON, 2007). 
As energias eólica e solar, por sua vez, por depender de questões físicas e climáticas, são mais eficientes em determinadas regiões. A eólica, apesar de ser uma excelente alternativa, depende da movimentação das massas de ar que não ocorre com intensidade suficiente em todas as regiões. Enquanto a energia solar, que tem como fonte de geração o sol, em um país tropical com alta incidência solar como o Brasil, se torna de grande interesse para implantação (ANEEL, 2002). O sol está na origem de quase todas as fontes de energia, mas para o aproveitamento direto de sua luz, são necessários dispositivos capazes de captar e armazenar essa energia. São conhecidas hoje três formas de captação direta de energia solar: os coletores térmicos, captores passivos de concentração e as células fotovoltaicas feitas a base de silício (SCARLATO; PONTIM, 2001; COELHO; RONSANI, 2019).

Acredita-se que a energia solar será a mais importante a longo prazo. As células fotovoltaicas apresentam um método extremamente promissor, pois além de minimizar impactos ambientais durante sua operação, se constituem como uma fonte primária inesgotável de energia (WALISIEWICZ, 2008). Destaca-se, por outro lado, significativos impactos decorrentes do processamento dos elementos que compõem as células (THORSTENSEN, 2013), além da problemática que envolve os posteriores descartes de baterias e placas, demonstrando ainda há muito a melhorar. No entanto, vale lembrar que a existência e manutenção do status quo da vida humana, por si, levam a constantes alterações dos parâmetros ambientais tornando importante o investimento em sistemas que sejam menos agressivos seja na sua implantação ou funcionamento.

O Brasil possui enorme potencial para gerar energia solar, e as vantagens se ampliam quando se trata da própria concessionária, pois as instalações de células nos centros urbanos aliviam picos de energia e evitam manutenções nas redes convencionais, além de promover empregos e desenvolvimento tecnológico (JARDIM et al., 2004). A grande dificuldade de implantação está relacionada aos custos que podem ser ressarcidos a longo prazo, porém a discussão se amplia para a competitividade do mercado, 
pois quando há grandes produções, os valores tendem a ser mais acessíveis (COSTA; SANTOS, 2017).

Outro setor que poderia trazer dificuldades para a implantação é o governamental, porém com a perspectiva de promover a difusão do sistema solar para evitar as complicações relacionadas aos combustíveis fósseis, há incentivos como o Programa de Desenvolvimento Energético dos Estados e Municípios (PRODEEM). O PRODEEM promove instalações de células fotovoltaicas em comunidades isoladas, onde a rede de energia comum não é distribuída para toda população. Outro programa, o "Luz para Todos", também utiliza as células fotovoltaicas, com o intuito de evitar o êxodo rural, caracterizado pela busca de melhores condições de vida nos centros urbanos (AGÊNCIA CANALENERGIA, 2018).

Em 2012, a Agência Nacional de Energia Elétrica - ANNEL, com o intuito de facilitar as instalações de sistemas fotovoltaicos instituiu a resolução normativa $n^{\circ}$ 482, de 17 de abril de 2012, que estabeleceu as condições gerais para o acesso de microgeração e minigeração distribuída aos sistemas de compensação e distribuição de energia elétrica (ANNEL, 2012). O incentivo sequencial foi em 2015, no qual o Ministério de Minas e Energia (MME) lançou o Programa de Desenvolvimento da Geração Distribuída de Energia Elétrica (ProGD), com o objetivo de impulsionar a geração de energia pela própria população, aumentando o emprego de energias renováveis, com destaque principalmente ao sistema solar fotovoltaico. Os investimentos para execução desse programa podem movimentar pouco mais de $\mathrm{R} \$ 100$ bilhões até 2030 (MME, 2016).

Neste cenário, a energia fotovoltaica com destaque para a minigeração e microgeração conectada à rede e suas vantagens ganham notoriedade entre os recursos renováveis, principalmente pela questão ambiental, desencadeando grande interesse em diversos segmentos da sociedade, como em setores corporativos, governamentais e acadêmicos (JARDIM, 2007). Diante dos fatos, torna-se extremamente relevante estudar essa energia limpa e seus usos, a fim de desfavorecer os combustíveis fósseis e beneficiar a qualidade de vida. Pequenos geradores são 
extremamente importantes para o desenvolvimento do país e são beneficiados com o retorno dos investimentos, além disso, os lucros futuros incentivam o consumidor a investir em outras tecnologias limpas promovendo qualidade de vida, benefícios para a biodiversidade e amplo desenvolvimento socioambiental.

Neste contexto, o estudo tem como objetivo avaliar a viabilidade técnica, socioambiental e econômica de um sistema solar fotovoltaico ligado à rede de distribuição e já implementado em um posto de combustível no município de Vinhedo, no estado de São Paulo, Brasil.

\section{Material e Métodos}

O trabalho fundamenta-se quanto aos procedimentos em estudo bibliográfico, com fontes de pesquisas primárias e secundárias, além disso, complementa-se pelo estudo de caso que busca reunir as principais particularidades do funcionamento das células fotovoltaicas no posto de combustível. Quanto aos objetivos, caracteriza-se por estudo descritivo com caráter qualitativo, a fim de evidenciar a valoração da utilização de sistemas fotovoltaicos em centros urbanos.

O trabalho iniciou-se com pesquisas bibliográficas e coleta de dados secundários em publicações científicas selecionadas por apresentarem relevância pertinente ao estudo. Os levantamentos buscaram por assuntos de minigeração e microgeração, relacionando as legislações vigentes e os programas governamentais brasileiros de incentivos lançados na última década. Para a busca dos artigos, utilizou-se banco de dados de periódicos, como o Google Acadêmico e Scielo, além de sites governamentais como o MME. Além disso, selecionou-se trabalhos com resultados e discussões sobre os sistemas fotovoltaicos e suas instalações especialmente em locais urbanos.

Em seguida foi realizado o estudo de caso no município de Vinhedo, estado de São Paulo - Brasil. A região é majoritariamente urbana, e sua densidade demográfica é estimada em 933,55 hab. $/ \mathrm{km}^{2}$ e o grau de urbanização é de $96,86 \%$ (SEAEDE, 2019). Trata-se de uma rede de três 
postos de combustíveis. A implantação do sistema de geração de energia fotovoltaica ligada à rede foi instalada em um dos postos que será denominado posto 1 . O posto 1 já contava com uma pequena instalação no lavador de carros, e com o intuito de ampliar o investimento, optou-se por expandir, no final do ano de 2017, as placas fotovoltaicas no posto e assim contemplar o consumo energético total.

Foram realizadas visitas técnicas no local, para conhecer o funcionamento do sistema de geração fotovoltaico implantado. Analisou-se, nessa etapa, a viabilidade técnica, econômica e socioambiental da instalação. A coleta de dados foi realizada de forma primária através de documentos fornecidos pelo proprietário e secundária a partir de informações complementares que foram levantadas em campo.

O objetivo do estudo é descritivo com caráter qualitativo, evidenciando-se o valor de contribuir com esclarecimentos que visem novas implantações de energias limpas e renováveis em estabelecimentos comerciais.

Conforme relacionado nas bibliografias, o consumidor/gerador pode suprir parcialmente ou totalmente a própria demanda, reduzindo assim, o valor da conta de energia e recuperando o investimento (SIQUEIRA, 2015). Para verificar a viabilidade econômica do sistema foram analisados em documentos fornecidos pelo proprietário o consumo anterior à instalação, que tinha apenas alguns painéis no lavador de carros já instalados, em comparação com o consumo posterior. Além disso, o tempo de retorno e o montante do investimento foram fatores imprescindíveis para saber 0 consumo de energia atualmente no estabelecimento.

Outro fator de extrema importância é o máximo aproveitamento da radiação solar, que pode variar ao longo do ano de acordo com a localização do endereço, bem como estação do ano e inclinação dos painéis, sendo que para essa constatação, verificou-se a radiação que incide no local (SIQUEIRA, 2015). 
Para a análise da viabilidade técnica, utilizou-se documentos fornecidos pela empresa que fez a instalação dos painéis fotovoltaicos no posto 1. A implantação selecionada para o caso estudado depende de profissionais e técnicas especializadas, sendo que uma vez instalado, o sistema entra em funcionamento automaticamente através da incidência dos raios solares. Destaca-se que o controle da produção pode ser feito online através de um aplicativo fornecido pela empresa.

Os sistemas fotovoltaicos de microgeração e minigeração utilizam a rede para acumular a energia gerada que está em excesso. O esquema representado na Figura 1 demonstra como é realizada a disposição dos equipamentos na instalação. A ligação é feita mediante interface eletrônica com inversores que devem respeitar as normas de segurança (NASCIMENTO, 2013).

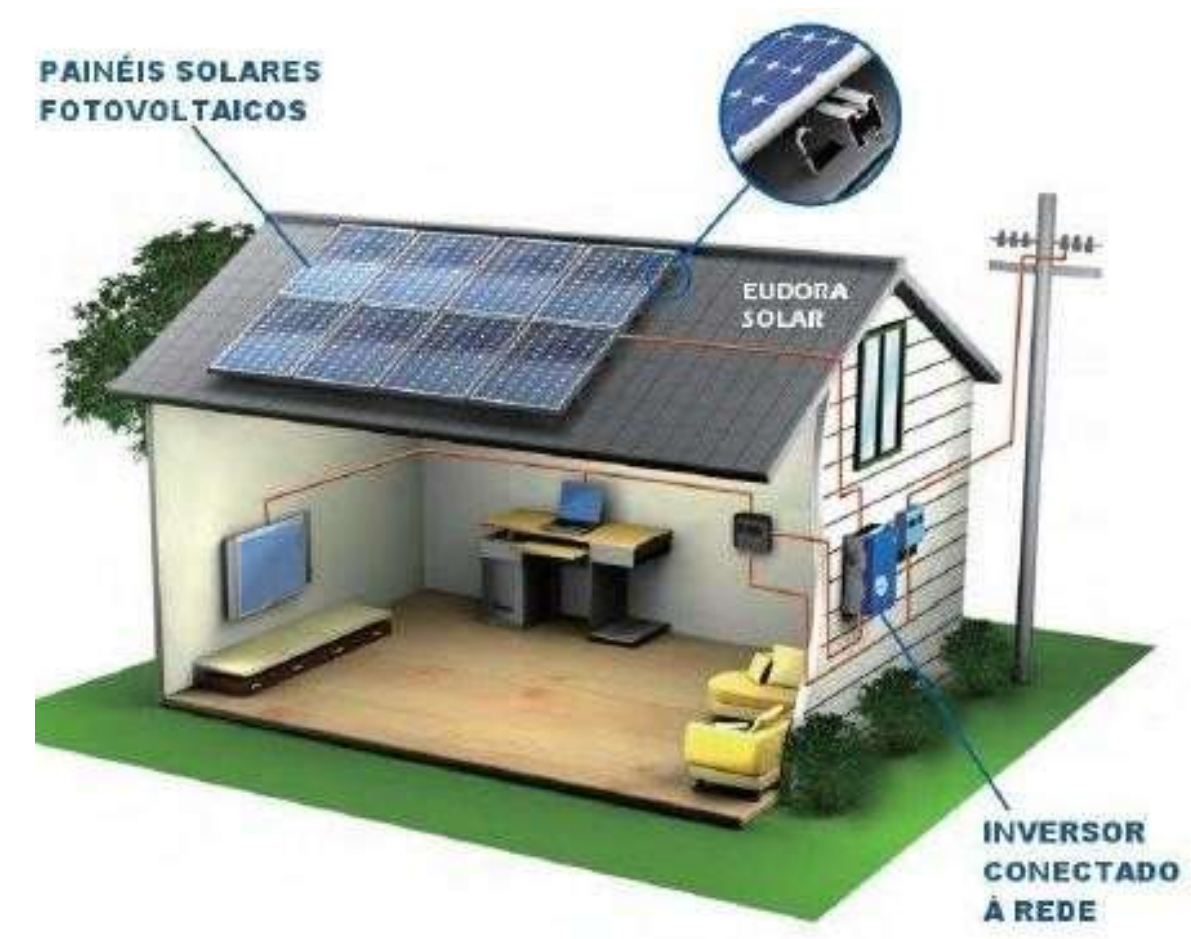

Figura 1. Sistema fotovoltaico ligado à rede elétrica. Fonte: Nascimento (2013).

Pela análise dos equipamentos, verificou-se ainda a eficiência e duração dos materiais. O silício cristalino é o material utilizado para construir os painéis fotovoltaicos atualmente. Essas células de silício cristalino podem 
ser classificadas em três tipos dependendo da forma que são fabricadas, podem se: monocristalino, policristalina e fita de silício. A eficiência da conversão varia de acordo com o tipo utilizado na instalação (NASCIMENTO, 2013).

A importância de implementar um sistema com energias renováveis e divulgar os benefícios atrelados incide em melhorias ambientais e em conhecimentos socioeconômicos, direcionados a população que tem interesse na implantação e utilização dessa fonte energética. Para verificar a questão social, analisou-se documentos fornecidos pela empresa e aplicouse um questionário impessoal para usuários anônimos do estabelecimento.

O questionário impessoal fornecido pelo proprietário do posto era composto por 6 perguntas relacionadas ao conhecimento sobre a energia fotovoltaica. O questionário foi realizado no ano de 2019 nas imediações dos postos 1, 2 e 3, com um total de 50, 25 e 25 pessoas participantes, respectivamente, em cada posto, que aceitaram participar da pesquisa quando solicitados. A cidade de Vinhedo-SP possui aproximadamente 79.000 habitantes, e estatisticamente optou-se por um amostragem aleatória, de uma população heterogênea, com nível de confiança de $95 \%$ e uma amostra de 100 pessoas, compondo uma margem de erro de $10 \%$.

A pesquisa buscou abordar a percepção das pessoas sobre ter um posto sustentável no município, além de levantar alguns dados sobre os conhecimentos dos clientes, em relação à energia solar.

Essa questão socioambiental expande os conhecimentos da população sobre tecnologias limpas e as necessidades de o meio ambiente precisar desse equilíbrio no meio urbano. A economia de carbono em um empreendimento desse porte é uma das grandes vantagens para a qualidade de vida da região.

\section{Resultados e discussão}

Com base nos dados fornecidos pelo proprietário, constatou-se o cenário anterior à implantação do sistema fotovoltaico no posto 1. A Tabela 
1 relaciona os dados do consumo geral em $\mathrm{kWh}$ dos outros postos de combustível da rede do proprietário na região, com a geração do sistema implantado no lavador de carros em meados de 2016 a meados de 2017.

Tabela 1. Dados de consumo energético anteriores à instalação do sistema fotovoltaico no autoposto 1.

\begin{tabular}{cccccc}
\hline Mês & $\begin{array}{c}\text { Lavador } \\
\text { kWh }\end{array}$ & $\begin{array}{c}\text { Posto 1 } \\
\text { kWh }\end{array}$ & $\begin{array}{c}\text { Posto 2 } \\
\text { kWh }\end{array}$ & $\begin{array}{c}\text { Posto 3 } \\
\text { kWh }\end{array}$ & $\begin{array}{c}\text { Geração } \\
\text { kWh }\end{array}$ \\
\hline Ago./16 & 840 & 4.975 & 14.270 & 8.720 & 1.545 \\
Set./16 & 795 & 4.006 & 13.140 & 9.560 & 1.258 \\
Out./16 & 945 & 3.900 & 14.060 & 8.720 & 1.546 \\
Nov./16 & 757 & 4.129 & 16.050 & 9.000 & 1.382 \\
Dez./16 & 561 & 4.186 & 15.190 & 9.560 & 783 \\
Jan./17 & 671 & 5.403 & 15.950 & 8.920 & 1.391 \\
Fev./17 & 713 & 4.810 & 14.010 & 8.280 & 1.598 \\
Mar./17 & 742 & 5.797 & 15.240 & 8.960 & 1.570 \\
Abr./17 & 831 & 4.818 & 14.070 & 9.000 & 1.712 \\
Mai./17 & 844 & 4.288 & 15.350 & 8.320 & 1.417 \\
Jun./17 & 942 & 3.564 & 12.890 & 8.040 & 1.291 \\
Jul./17 & 1.159 & 3.655 & 14.560 & 9.520 & 1.343 \\
\hline Média & $\mathbf{8 1 7}$ & $\mathbf{4 . 4 6 1}$ & $\mathbf{1 4 . 5 6 5}$ & $\mathbf{8 . 8 8 3}$ & $\mathbf{1 . 4 0 3}$ \\
\hline
\end{tabular}

Fonte: Rede de postos de combustíveis, (2019).

Conforme constatado, o consumo do lavador de carros apresenta uma média mensal de 817 kWh, além disso há para este proprietário o consumo relacionado dos outros postos. A geração dos painéis em cima do lavador apresenta uma produção média de 1.403 kWh. Além de suprir a necessidade da instalação do lavador de carros, a energia excedente pode ser utilizada para suprir a necessidade mensal do próprio posto, sendo assim, o montante final de consumo de energia elétrica é reduzido. Conforme o retorno, os benefícios do investimento supriram a demanda necessária, sendo projetado um sistema para satisfazer a demanda de energia do posto 1 como um todo. Neste mesmo período foram verificados os gastos mensais que a rede de postos tinha com a distribuidora de energia, conforme Tabela 2.

A média de gastos mensais com os 3 postos de combustíveis é de $\mathrm{R} \$ 16.290,45$. O investimento em um sistema de energia fotovoltaica, assim, implica em uma economia abundante a longo prazo, conforme afirma Costa 
e Santos (2017). Apesar do sistema fotovoltaico implantado no lavador ser uma pequena parcela deste montante, o retorno eficiente foi significativo e tornou viável a implantação de mais painéis fotovoltaicos nas instalações do posto de combustível. A princípio, a implantação se expandiu para o posto 1 e futuramente, conforme o retorno, será expandido para os outros postos de combustíveis da rede.

Tabela 2. Gastos mensais anteriores a implantação do sistema fotovoltaico.

\begin{tabular}{lcccc}
\hline Mês & $\begin{array}{c}\text { Posto } \mathbf{1} \\
\mathbf{R} \$\end{array}$ & $\begin{array}{c}\text { Posto } 2 \\
\mathbf{R} \$\end{array}$ & $\begin{array}{c}\text { Posto 3 } \\
\mathbf{R} \$\end{array}$ & $\begin{array}{c}\text { Total } \\
\mathbf{R} \$\end{array}$ \\
\hline Ago./16 & $3.268,08$ & $9.373,96$ & $5.728,17$ & $18.370,21$ \\
Set./16 & $2.636,35$ & $8.657,43$ & $6.291,44$ & $17.585,22$ \\
Out./16 & $2.586,48$ & $9.324,59$ & $5.783,10$ & $17.694,17$ \\
Nov./16 & $2.273,74$ & $8.838,74$ & $4.956,30$ & $16.068,78$ \\
Dez./16 & $2.235,84$ & $8.112,98$ & $5.106,01$ & $15.454,83$ \\
Jan./17 & $2.961,38$ & $8.742,20$ & $4.889,05$ & $16.592,63$ \\
Fev./17 & $2.575,76$ & $7.502,36$ & $4.433,94$ & $14.512,06$ \\
u Mar./17 & $3.201,10$ & $8.415,55$ & $4.947,71$ & $16.564,36$ \\
t Abr./17 & $2.588,71$ & $7.559,81$ & $7.835,70$ & $17.984,22$ \\
r Mai./17 & $2.402,14$ & $8.599,07$ & $4.660,86$ & $15.662,07$ \\
Jun./17 & $1.970,84$ & $7.128,71$ & $4.446,12$ & $13.545,67$ \\
OJul./17 & $2.036,20$ & $8.111,38$ & 5303,59 & $15.451,17$ \\
\hline Totais & $\mathbf{3 0 . 7 3 6 , 6 2}$ & $\mathbf{1 0 0 . 3 6 6 , 7 8}$ & $\mathbf{6 4 . 3 8 1 , 9 9}$ & $\mathbf{1 9 5 . 4 8 5 , 3 9}$ \\
\hline
\end{tabular}

Fonte: Rede de postos de combustíveis, (2019).

A instalação foi realizada conforme as características da localidade, neste aspecto a radiação solar é de extrema importância para a geração suprir o consumo (NASCIMENTO, 2013). Com isso, verifica-se conforme o Gráfico 1, que a radiação que incide no município de Vinhedo, apesar da queda nos meses de maio, junho e julho, pode ser considerada estável durante o ano.

Constata-se que ao longo do ano de 2017 a radiação constante permitiu uma excelente produção de energia para o retorno do investimento ser eficiente. De acordo com as informações analisadas, implantaram-se módulos com orientação de 125 graus por 305 graus. Os painéis instalados podem ser analisados na Figura 2. 


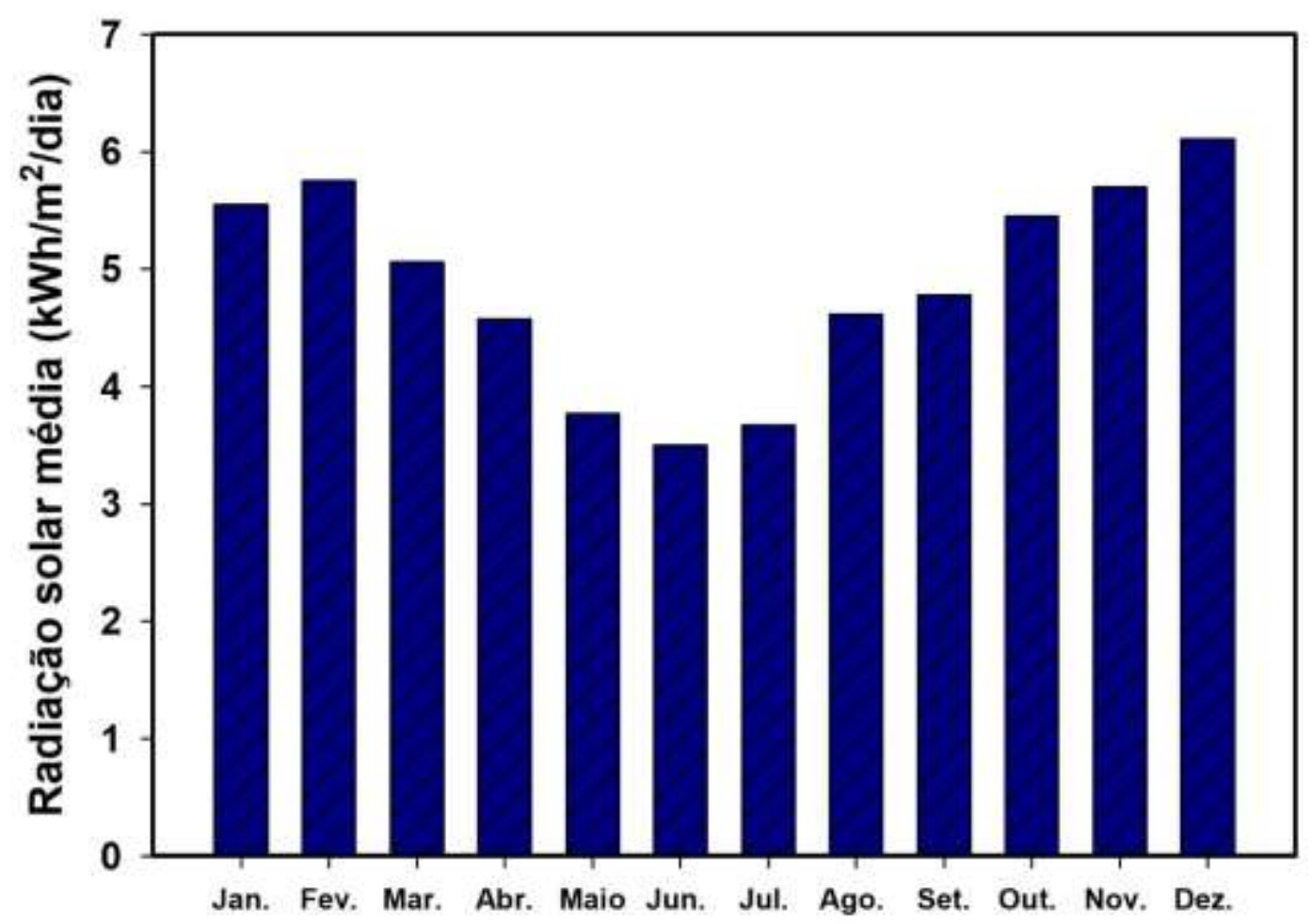

Gráfico 1. Radiação solar diária média no ano 2017 no município de Vinhedo, SP. Fonte: Cresesb, (2017).

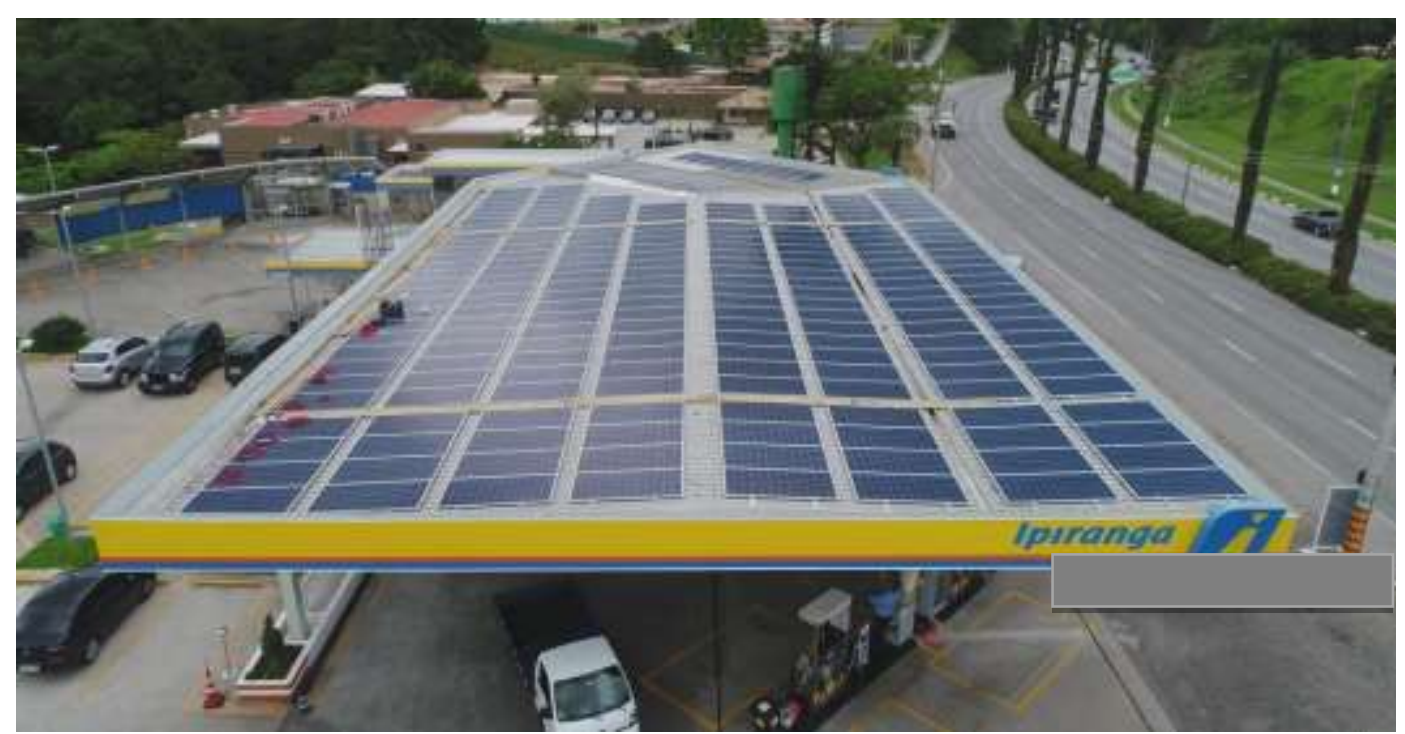

Figura 2. Painéis solares implantados no posto 1. Fonte: Solucione, (2019).

Foram instalados 160 painéis de $315 \mathrm{~W}, 2$ inversores de $5 \mathrm{kwp}$ /1MPPT e 1 inversor de 12kwp /2MPPT. A inclinação dos painéis foi de 4\% com orientação para sudoeste/noroeste. São aproximadamente 85,08 kWp instalados, gerando uma média de $10.000 \mathrm{kWh} / \mathrm{mês,} \mathrm{esse} \mathrm{sistema} \mathrm{é}$ 
classificado segundo as especificações da ANEEL (2012) como microgerador por apresentar a potência de pico menor que $100 \mathrm{kWp}$. Os painéis transformam a irradiação solar em energia elétrica e o inversor transforma a energia gerada para ser utilizada no local, sem necessidade de modificações na instalação elétrica atual (SOLUCIONE, 2019). A produção não consumida é injetada automaticamente na rede da distribuidora, gerando créditos na conta de luz para utilização posterior conforme afirmado por Costa e Santos (2017).

No caso do posto 1, os créditos que sobram são compensados em outro posto da rede. Logo o retorno financeiro tem sido um pouco mais alto para o empreendedor. Em análise do ano de 2018, após a implantação, verificou-se, conforme Tabela 3, a economia acumulada através dos meses, considerando a tarifa do ano que variou em torno de $0,62 \mathrm{R} \$ / \mathrm{kWh}$.

Os valores cedidos foram calculados pela simples multiplicação do valor de kWh gerado pela tarifa no mês (considerando a taxa aplicada nas contas), e, assim, foram expostos os valores que deveriam ter sido cobrados no caso do consumo da rede.

Tabela 3. Geração de energia e economia após a implantação do sistema fotovoltaico no ano de 2018.

\begin{tabular}{|c|c|c|c|}
\hline Mês & Geração kWh & Economia R\$ & \\
\hline Jan./18 & 7.826 & $4.227,33$ & \\
\hline Fev./18 & 6.168 & $3.622,56$ & \\
\hline Mar./18 & 6.036 & $3.086,46$ & \\
\hline Abr./18 & 5.309 & $3.018,95$ & \\
\hline Mai./18 & 5.101 & $3.134,64$ & \\
\hline Jun./18 & 4.175 & $2.598,07$ & \\
\hline Jul./18 & 4.793 & $3.108,21$ & \\
\hline Ago./18 & 4.495 & $2.926,55$ & \\
\hline Set./18 & 5.366 & $3.442,38$ & \\
\hline Out./18 & 6.064 & $3.810,73$ & \\
\hline Nov./18 & 5.472 & $3.952,32$ & \\
\hline Dez./18 & 6.970 & $4.531,10$ & \\
\hline Média & 5.648 & $41.459,30$ & $<--$ Total \\
\hline
\end{tabular}

Fonte: Rede de postos de combustíveis, (2019). 
Com a análise desses dados, nota-se que a implantação representou uma economia de $R \$ 41.459,31$ reais ao longo de 1 ano. Para essa verificação, analisa-se a geração de energia através das placas fotovoltaicas e o consumo dessa energia mensalmente. $O$ valor resultante da economia é a síntese de quanto seria gasto caso o consumo fosse pela distribuidora convencional. $O$ investimento neste sistema foi de $R \$$ 170.000,00 (considerando equipamentos e instalação), portanto, o valor da implantação será ressarcido ao longo de aproximadamente 4 anos. Do ponto de vista econômico, a instalação apresentou um retorno eficiente já no ano de 2018 e as projeções para 2019 acompanharam o padrão.

Para a implantação foi utilizado o silício monocristalino, este material é indicado por apresentar a melhor eficiência energética, que varia de $13 \%$ a $17 \%$ e a maior vida útil que varia de 25 a 30 anos. Os outros materiais são inferiores nesses quesitos, a fita de silício apresenta eficiência de $11 \%$ e as células policristalinas apresentam eficiência de 10 a 14\% com vida útil de 20 a 25 anos (NASCIMENTO, 2013). Verifica-se, por meio dos documentos fornecidos pelo proprietário, que a eficiência das placas do posto 1 é de $17 \%$ com durabilidade média de 25 anos, portanto, os equipamentos apresentam excelente viabilidade técnica.

Para verificar a questão social, analisou-se um questionário impessoal realizado no ano de 2019 nas imediações dos postos 1, 2 e 3, fornecido pelo proprietário da rede de postos. Foram abordadas 100 pessoas e as questões eram relacionadas apenas a conhecimentos sobre energia fotovoltaica, conforme evidenciado na Tabela 4.

$\mathrm{Na}$ primeira pergunta onze dos cinquenta entrevistados responderam que desconheciam sobre o assunto. $\mathrm{Na}$ segunda pergunta vinte e seis entrevistados desconheciam que o posto 1 produzia sua própria energia. Esse resultado demonstra a necessidade de divulgação desse cenário, a partir de ações promocionais e informativas para o público.

É nítido que todos identificam a importância de existir um posto sustentável no município, fato que rendeu elogios à iniciativa, além de ser 
exemplo para outros estabelecimentos na região investirem em energias fotovoltaicas e outros sistemas sustentáveis. Sugere-se que os próprios proprietários desses estabelecimentos invistam nessa divulgação, visto que isso possibilita maiores ganhos socioambientais e econômicos, por criar um laço, familiarizar os clientes com a política de sustentabilidade adotada pela empresa. Dessa forma, pode se criar um vínculo de fidelização do cliente, que se sentirá mais atraído por abastecer em uma empresa que colabora a sustentabilidade ambiental do seu município.

Tabela 4. Questionário impessoal fornecido pelo proprietário dos postos e as porcentagens de respostas da amostra de 100 pessoas.

\begin{tabular}{ccc}
\hline Questões & \multicolumn{2}{c}{ Respostas } \\
\cline { 2 - 3 } & Sim (\%) & Não (\%) \\
\hline Você conhece sobre as energias limpas? & 78 & 22 \\
\hline $\begin{array}{c}\text { Você sabia que o posto 1 produz sua } \\
\text { própria energia? }\end{array}$ & 52 & 0 \\
\hline $\begin{array}{c}\text { É importante a existência de um posto } \\
\text { sustentável no município? }\end{array}$ & 100 & 0 \\
\hline $\begin{array}{l}\text { Você acha que estabelecimentos com } \\
\text { sistema fotovoltaicos podem contribuir } \\
\text { para as questões socioeconômicas?" }\end{array}$ & 100 & 0 \\
\hline $\begin{array}{c}\text { Você acha que o uso da energia solar } \\
\text { colabora na redução de impactos } \\
\text { ambientais? }\end{array}$ & 100 & 63 \\
\hline $\begin{array}{c}\text { Você implantaria um sistema fotovoltaico } \\
\text { na sua residência? }\end{array}$ & 37 & \\
\hline
\end{tabular}

Quando indagados sobre a importância dos sistemas fotovoltaicos na contribuição das questões socioeconômicas, todos os participantes responderam de maneira positiva, mas na maioria dos casos relacionada à implantação de energias fotovoltaicas em regiões isoladas e vinculada a benefícios ambientais. Algo que foi confirmado com a próxima questão, onde os entrevistados quando questionados sobre a energia solar colaborar na redução de impactos ambientais, responderam de maneira positiva, porém muitos faziam relação à questão dos gases do efeito estufa. 
Destaca-se, no entanto que a implantação de sistemas fotovoltaicos nos centros urbanos é eficiente e necessária para o desenvolvimento socioeconômico nas cidades. A energia solar é uma fonte de energia renovável e constante, que não emite gases e não gera impactos ambientais. Esse sistema irá reduzir o consumo de energia elétrica, e em função do tempo, o que foi investido será revertido por essa economia, e por fim irá trazer redução nos gastos totais do estabelecimento. Ademais, as placas fotovoltaicas necessitam de baixa manutenção, tem longa vida útil e é um sistema silencioso; e pensando no Brasil seria uma ótima fonte de energia renovável a ser investida pelas organizações, visto que o país possui clima tropical.

E por fim, o último questionamento indagou sobre implantar um sistema fotovoltaico na própria residência caso houvesse oportunidade. Infelizmente, nesta questão, as respostas não foram unânimes e muitos clientes responderam que não. Em um panorama que recursos renováveis são uma necessidade para o futuro, verifica-se a necessidade de maiores discussões e divulgações para os cidadãos dos benefícios da utilização de sistemas fotovoltaicos, fortalecendo assim a sua adoção e a conscientização ambiental da população.

Além disso a acessibilidade depende dos custos dos equipamentos e, conforme afirmam Costa e Santos (2017), as projeções para o futuro relacionam o aumento da produção com a baixa dos custos, o que ofereceria essa oportunidade à grande massa da população, acrescenta-se ainda nesse sentido, que os incentivos e subsídios para tornar a energia fotovoltaica acessível devem partir de parcerias público-privadas (SIQUEIRA, 2013).

A iniciativa de implantar uma tecnologia limpa no meio urbano, representa enorme diferencial ambiental para o empreendimento que incorpora em suas atividades grandes passivos. Nesse sentido, a diminuição dos gases poluentes à atmosfera como $\circ \mathrm{CO}_{2}$, que causam alterações climáticas é de grande importância para o meio socioambiental (JARDIM, 2007). Com base nos dados fornecidos e já calculados pelo proprietário para 
fins de buscar benefícios e divulgar resultados, a implantação apresentou no ano de 2018 uma economia de 22 toneladas de $\mathrm{CO}_{2}$ com a perspectiva do mesmo montante para 2019. Destaca-se ainda a possibilidade de inserir certificações ambientais, entretanto, como não há incentivos no município a alternativa não se apresentou viável.

Embora o investimento para a implantação do sistema tenha sido alto, o mesmo demonstrou ser eficaz no âmbito econômico. Conforme as economias mencionadas, a projeção de retorno financeiro em quatro anos e a vida útil dos painéis de aproximadamente 25 anos, tornam a viabilidade a longo prazo irrefutável, mesmo levando em consideração os reajustes de $\mathrm{kW} / \mathrm{h}$ das concessionárias.

Apesar de existirem programas governamentais como o Plano Decenal de Expansão de Energia 2030 - PDE 2030, que indica as perspectivas da expansão do setor energético para de dez anos (2021 2030), dentro de uma visão integrada para os recursos energéticos, falta divulgação. Esse documento fornece indicações para aumento e planejamento do setor energético, enfocando a esfera econômica, estratégica e socioambiental, a fim de aumentar a confiabilidade, enfocar os benefícios econômicos, aumentar a competitividade empresarial, reduzir os custos de produção, otimizar o uso dos recursos energéticos disponíveis, aumentar a oferta de energia para população e reduzir os potenciais impactos ambientais (MME, 2021).

Contudo, os benefícios da energia solar ainda são desconhecidos por muitos, e no Brasil ainda existe uma baixa aderência à sua implantação. A implementação de incentivos como baixas de tributação aos empreendimentos que aderem a tecnologias limpas é hoje e para o cenário futuro de grande importância. A discussão sobre a sustentabilidade deve chegar aos municípios e empreendedores em formato beneficente, deste modo, incorpora-se às mudanças relacionadas à proteção e prevenção do meio em todos os setores, aliviando a preocupação crescente sobre o meio ambiente e a escassez dos recursos. 


\section{Conclusões}

Conclui-se que o sistema de energia solar fotovoltaico implantado em um posto de combustíveis no município de Vinhedo-SP, é eficiente do ponto de vista econômico, técnico e socioambiental. A análise básica dos dados mostrou que a quitação dos custos do investimento e, consequente, retorno financeiro ocorre em quatro anos após a implantação. A implantação e funcionamento do sistema não demonstrou impactos ambientais. Mesmo com todos os benefícios mostrados, verificou-se que a população não tem conhecimento destes. Por isso, a conscientização da população deve ter ênfase em todos os sentidos, para haver essa quebra de paradigma. Inserir novas tecnologias limpas e acessíveis no mercado, contribui com as gerações futuras e com a existência da biodiversidade. Sugere-se que os próprios proprietários do estabelecimento invistam nessa conscientização como forma de ampliar os ganhos econômicos, ambientais e sociais com o investimento realizado. Por fim, a preocupação com as causas ambientais deve ter destaques também governamentais com incentivos e políticas públicas que possam alavancar o acesso desses equipamentos para todos. 


\section{Referências}

AGÊNCIA CANALENERGIA. Sistemas fotovoltaicos com recursos do luz para todos são instalados no PA. Solar energy fórum, 2018. Disponível em:

http://www2.ctee.com.br/brasilsolarpower/2016/zpublisher/materia/?url=siste mas-fotovoltaicos-com-recursos-do-luz-para-todos-s-o-instalados-no-pa20180521. Acesso em: 26 abr. 2019.

AGÊNCIA NACIONAL DE ENERGIA ELÉTRICA - ANEEL. Atlas de Energia Elétrica do Brasil. Brasília: CEDOC, 2002.

AGÊNCIA NACIONAL DE ENERGIA ELÉTRICA - ANEEL. Resolução Normativa n. 482, de 17 de abril de 2012. Estabelece as condições gerais para o acesso de microgeração e minigeração distribuída aos sistemas de distribuição de energia elétrica, o sistema de compensação de energia elétrica, e dá outras providências. Diário Oficial da União, Brasília, DF, 2012.

CENTRO DE REFERÊNCIA PARA AS ENERGIAS SOLAR E EÓLICA SÉRGIO DE S. BRITO - CRESESB. Potencial Solar. CRESESB, 2018. Disponível em: http://www.cresesb.cepel.br/. Acesso em: 22 abr. 2019.

COELHO, Ediomar Cesar; RONSANI, Greice Scarduelli. Utilização de Energia Solar nas Indústrias. Revista de Ciências Exatas e Tecnologia, v. 14, n. 14, p. 06-08, 2020. Editora e Distribuidora Educacional. http://dx.doi.org/10.17921/1890-1793.2019v14n14p06-08

COSTA, J. F. I.; SANTOS, P. F. M. Modelos Geradores de Energia Fotovoltaica: uma análise de viabilidade no estado do Goiás. Revista Brasileira de Energia Solar, v. 3, n. 2, 2017.

GOLDEMBERG, J. LUCON, O. Energias renováveis: um futuro sustentável. REVISTA USP, n.72, p. 6-15, 2006-2007.

JARDIM, C. S. et al. O potencial dos sistemas fotovoltaicos interligados à rede elétrica em áreas urbanas: dois estudos de caso. In: Encontro de Energia no Meio Rural. Proceedings online, v. 5, 2004.

JARDIM, C. S. A inserção da geração solar fotovoltaica em alimentadores urbanos enfocando a redução do pico de demanda diurno. 2007. 148 f. Tese (Doutorado em Engenharia Civil) - Universidade Federal de Santa Catarina, Florianópolis, 2007.

MINISTÉRIO DE MINAS E ENERGIA - MME. MME inaugura 1' Usina Solar distribuída em prédio do Governo Federal. MME, 2016. Disponível em: http://www.mme.gov.br/web/guest/todas-as-noticias. Acesso em: 22 abr. 2019.

MINISTÉRIO DE MINAS E ENERGIA - MME. Plano Decenal de Expansão de Energia 2030. Brasil-MME, 2021. Disponível em: 
https://www.epe.gov.br/sites-pt/publicacoes-dados-

abertos/publicacoes/PublicacoesArquivos/publicacao-

490/PDE\%202030_RevisaoPosCP_rv2.pdf. Acesso em: 12 maio 2021.

NASCIMENTO, M. A. P. Avaliação de qualidade de energia de um sistema fotovoltaico numa rede elétrica. Docplayer, 2013. Disponível em: $<$ https://docplayer.com.br/7002635- Avaliacao-de-qualidade-de-energia-deum-sistema-fotovoltaico-numa-rede-eletrica.html>. Acesso em: 22 abr. 2019.

SCARLATO, F. C.; PONTIN, J. A. Energia para o Século XXI. São Paulo: Editora Ática, 2001.

SEAEDE. Governo do Estado de São Paulo. Perfil dos Municípios Paulistas. SEAEDE, 2019. Disponível em: < http://www.perfil.seade.gov.br/?>. Acesso em: 15 abr. 2019.

SIQUEIRA, M. P. Viabilidade da Microgeração de Energia Elétrica em uma residência por um Sistema Composto por Painéis Fotovoltaicos Conectados à Rede. 2013. Trabalho de conclusão de curso de Engenharia Civil. Universidade Federal do Rio de Janeiro. Rio de Janeiro, 2013.

SIQUEIRA, L. M. Estudo do Dimensionamento e da Viabilidade Econômica de Microgerador Solar Fotovoltaico Conectado à Rede Elétrica. 2015. 51 f. Trabalho de conclusão (Engenharia Elétrica) Faculdade de Engenharia, Universidade Federal de Juiz de Fora, Juiz de Fora, 2015.

SOLUCIONE. A energia solar em suas mãos. Solucione, 2019. Disponível em: <https://www.solucione.eco.br/>. Acesso em: 24 abr. 2019.

THORSTENSEN, A.E. Analysis of an Intermediate Band SolarCell System: Based on Systems Engineering Principles. Chemical Engineering and Biotechnology, UK, December 2013. Disponível em: < https://core.ac.uk/download/pdf/30818478.pdf>. Acesso em: 10 maio 2021.

WALISIEWICZ, M. Energia Alternativa: solar, eólica, hidrelétrica e de biocombustíveis. São Paulo: Publifolha, 2008. 